\title{
Synthetic Cooling Agents in US-marketed E-cigarette Refill Liquids and Disposable E-cigarettes: Chemical Analysis and Risk Assessment.
}

Sairam V. Jabba, DVM, PhD ${ }^{* 1,2}$; Hanno C. Erythropel, PhD ${ }^{* 2,3}$; Deyri Garcia Torres ${ }^{2}$; Lauren

A. Delgado 2; Paul T. Anastas 4; Julie B. Zimmerman PhD ${ }^{2,3}$; and Sven-Eric Jordt, PhD 1,2,5

1: Department of Anesthesiology, Duke University School of Medicine, Durham, NC

2: Yale Center for the Study of Tobacco Products (YCSTP), Department of Psychiatry, Yale

School of Medicine, New Haven, CT

3: Department of Chemical and Environmental Engineering, Yale University, New Haven, CT;

4: School of Public Health, Yale University, New Haven, CT;

5: Corresponding author

* These authors contributed equally

Address for Corresponding Author

Sven-Eric Jordt, PhD (sven.jordt@duke.edu)

Department of Anesthesiology

Duke University School of Medicine

3 Genome Ct.

Durham, NC 27710-3094 


\begin{abstract}
:
Background: Menthol, through its cooling sensory effects, facilitates smoking and tobacco product initiation, which is reflected by the high popularity of mint/menthol-flavored E-cigarettes. More recently, E-cigarette vendors started marketing synthetic cooling agents as additives that impart a cooling effect but lack a characteristic minty odor. Knowledge about content of synthetic coolants in US-marketed E-cigarette products and associated health risks is limited.
\end{abstract}

Methods: E-liquid vendor sites were searched with the terms "koolada", "kool/cool", "ice", or WS-3/WS-23, denoting individual cooling agents, and relevant refill E-liquids were purchased. "Ice" flavor varieties of Puffbar, the popular disposable E-cigarette brand, were compared with non-"Ice" varieties. E-liquids were characterized, and synthetic coolants quantified using GC/MS. Margin of exposure (MOE), a risk assessment parameter, was calculated to assess the risk associated with synthetic coolant exposure from E-cigarette use.

Results: WS-3 was detected in $24 / 25$ of the identified refill E-liquids (24/25), while almost all Puffbar disposables flavor varieties contained WS-23 (13/14), with 5/14 also containing WS-3, in both "Ice"- and non-“Ice" flavors. Modeling consumption of WS-3 from vaped E-liquids resulted in MOEs below the safe margin of 100 for most daily use scenarios (3-mL:14/25 E-liquids; 5mL:18/25; 10-mL:20/25 ). MOEs for WS-23 from 11/13 Puffbar products were $\leq 100$ in all use scenarios.

Conclusions: Synthetic cooling agents (WS-3, WS-23) were present in US-marketed E-cigarettes, at levels that may result in consumer exposures exceeding safety thresholds set by regulatory agencies. Synthetic cooling agents are not only found in mint-or menthol-flavored products, but also in fruit- and candy-flavored products, including popular disposable E-cigarette products such as Puffbar. 
Implications: Synthetic cooling agents are widely used in "kool/cool"- and "ice"-flavored E-liquids and in E-liquids without these labels, both as a replacement for menthol or to add cooling 'notes' to non-menthol flavors. These agents may be used to bypass regulatory limits on menthol content in tobacco products. Since synthetic cooling agents are odorless, they may not fall under the category of "characterizing flavor", potentially circumventing regulatory measures based on this concept. Regulators need to consider the additional health risks associated with exposure to synthetic cooling agents. 


\section{Introduction}

Additives and flavors are added to tobacco products to counteract the harshness, sensory irritation and bitter tastes associated with tobacco and nicotine. In the United States, the Family Smoking Prevention and Tobacco Control Act (FSPTCA) of 2009 authorized the Food and Drug Administration (FDA) to regulate constituents, additives, and flavors in tobacco products. The FSPTCA banned the sales of flavored cigarettes, with the exception of menthol cigarettes. Menthol in tobacco products is well understood to reduce harshness, impart a pleasant minty and cooling flavor and increase palatability ${ }^{1,2}$. By altering the sensory perception and appeal of these products, menthol affects tobacco and nicotine use behaviors such as initiation, dependence, abuse liability and reduces the ability to quit, especially among the youth and young adults ${ }^{3}$. Menthol in tobacco products is also known to increase tobacco use disparities, with $85 \%$ of African American smokers using menthol cigarettes ${ }^{3,4}$. The US FDA announced in May 2021 that it will issue a rule that will ban menthol cigarettes ${ }^{5}$. Menthol is also a popular flavor in E-cigarettes, especially since the FDA banned flavored, closed pod systems such as Juul, except for menthol and tobacco flavors ${ }^{6}$. After Juul "Mint" pods were removed, sales of menthol pods increased 6-fold during August 2019 and May 2020 (10.7\% to 61.8\%) ${ }^{7,8}$.

In a recent study we compared menthol concentrations in menthol-flavored pods marketed by Juul in the US, Canada and Europe ${ }^{9}$. In addition to menthol, the Europeanmarketed menthol pods were found to contain the synthetic cooling agent WS-3, while the US and Canadian pods did not ${ }^{9}$. Synthetic cooling agents share the sensory cooling effects of menthol, but lack menthol's strong minty odor ${ }^{10,11}$. These agents were developed beginning in the 1970s, to replace menthol in body care and foods. In the 1970 s and 80s, the tobacco industry including R.J. Reynolds and Phillip Morris, carried out consumer tests with cigarettes containing synthetic cooling agents, to impart a "cooling without menthol" experience ${ }^{10-13}$. More recently, an analysis of combustible cigarettes (both menthol and non-menthol) marketed in Germany detected WS-3, indicating that coolants other than menthol are added to tobacco products ${ }^{14,15}$. Currently, there exists a gap in knowledge about the presence and quantities of synthetic cooling agents such as WS-3 and WS-23 in US-marketed E-cigarettes and E-cigarette refill liquids ("E-liquids"). In addition to being added by manufacturers, synthetic cooling agents are also sold for (므-It-Yourself) DIY users, often under the name "Koolada" 16,17.

We recently reported that some menthol-flavored E-liquids contain unsafe levels of pulegone, a carcinogenic mint flavorant banned by FDA in food, raising concerns about the unregulated addition of mint- and cooling flavorants to E-cigarettes ${ }^{18,19}$. While synthetic cooling 
agents such as WS-3 are classified by the Flavor Extracts Manufacturers Associaton (FEMA) as GRAS (Generally Recognized As Safe), this applies only to their intended use in oral care and food products, but not to E-cigarette use resulting in inhalational exposure ${ }^{20}$. The Joint Expert Committee on Food Additives (JEFCA) of the World Health Organization (WHO) established a threshold of concern of $90 \mu \mathrm{g} /$ day/person for intake of WS-3 and related compounds, a level that is often exceeded by consumers ${ }^{21}$. JECFA established a No-Observed-Adverse-EffectLevel (NOAEL) of $8 \mathrm{mg} / \mathrm{kg}$-bw for WS-3 ${ }^{21,22}$. For WS-23, a NOAEL of $5 \mathrm{mg} / \mathrm{kg}$-bw was determined for oral administration, with higher doses causing kidney and liver lesions ${ }^{21,23}$. A WS-23 inhalation exposure study by an E-liquid manufacturer determined a NOAEL of 29 $\mathrm{mg} / \mathrm{kg}$-bw (342 mg/m3) ${ }^{24}$. In vitro genotoxicity studies in mammalian cells demonstrated WS-23 to be clastogenic (i.e., inducing disruption or breakages of chromosomes), leading to a call by JECFA for additional toxicological studies to evaluate the safety of WS-23 ${ }^{21}$. Due to their evident toxicity and increased use in E-cigarettes, it is critical to evaluate the potential health risks associated with synthetic coolant exposure in chronic users.

In the present study, we determined the levels of synthetic cooling agents (WS-3, WS23) as well as three important peppermint- and spearmint flavor chemicals (menthol and menthone, and carvone, respectively) in US-marketed refill E-liquids and in disposable E-cigarettes of the brand Puffbar, one of the leaders in this rapidly growing category especially popular among middle and high school students ${ }^{7,8}$. We also assessed the health risk associated with synthetic coolant exposure via E-cigarette use by calculating the Margin of Exposure (MOE), a risk assessment parameter, for a range of product use scenarios modeling low, moderate and frequent E-cigarette use. 


\section{Materials and Methods:}

Analysis of synthetic cooling agents and other flavor content in US-marketed E-cigarette liquids and their aerosols:

\section{E-liquid selection}

E-cigarette vendor websites keyword searches for "koolada", "kool", "WS-3", and "WS-23" were carried out to identify E-liquids potentially containing synthetic coolants, and identified products were purchased directly from vendors in 2019 and 2020; this also included one product ("Agent Cool”) sold as a concentrate for do-it-yourself (DIY) users. In addition, previously purchased menthol/mint/spearmint/wintergreen E-liquids (2019) were re-analyzed for synthetic coolant presence. In early 2020, all available flavors of "Puffbar" were purchased from puffecig.com due to the frequent occurrence of the word "cool" in Puff bar flavor names (see Table 1 and 2 for an overview).

\section{E-liquid chemical analysis}

E-liquids were analyzed using an established GC-MS method and selected compounds were quantified using an established GC-FID method ${ }^{25}$. To do so, commercially available standards of N-Ethyl-p-menthane-3-carboxamide, WS-3 (99\%; CAS No. 39711-79-0), (S)nicotine (>99\%; CAS No. 54-11-5), (DL)-menthol (99\%; 89-78-1), (D)-carvone (>96\%; CAS No. 2244-16-8; all Sigma-Aldrich, St. Louis, MO), 2-isopropyl-N,2,3-trimethylbutyramide, WS-23 (>98\%; CAS No. 51115-67-4, TCI, Portland, OR), and (L)-menthone (97\%; CAS No. 14073-973; Alfa Aesar, Haverhill, MA) were used to construct calibration curves in the relevant concentration range. In brief, samples were diluted in $1 \mathrm{~mL}$ of methanol [JT Baker, Center Valley, PA] containing $1 \mathrm{~g} / \mathrm{L}$ of 1,4-dioxane [Alfa Aesar] as internal standard (IS) and injected; the detailed analytical methods have been described previously ${ }^{25}$.

\section{Coolant carryover analysis}

To assess the carryover of the synthetic coolants WS-3 and WS-23 from refill E-liquids to E-cigarette-generated aerosol, the Suorin iShare refillable pod E-cigarette device was used $(3.7 \mathrm{~V}, 1.8 \mathrm{Ohm}$, resulting max. power $7.6 \mathrm{~W})$, which was attached via a custom-3D printer connector to a previously described house-built vaping machine ${ }^{26}$. In brief, the device is controlled by a programmable Arduino board that activates a micro-diaphragm pump at an operator-defined puff length, inter-puff break, and number of puffs. A microneedle valve in combination with a flow meter [Omega, Norwalk, CT] is used to control the flow rate. Generated aerosol was trapped by a series of liquid nitrogen-chilled cold-finger traps. Carryover was 
determined in triplicate (three separate cartridges), and percent carryover was calculated as coolant content in trapped aerosol over coolant content of consumed liquid. A total of 9 carryover experiments were performed ( 7 in triplicate, 2 singular; $n=23$ ), with the following puffing regimen: 20 puffs, $2 \mathrm{~L} / \mathrm{min}$ flow rate, $2.4 \mathrm{~s}$ puff length, $80 \mathrm{~mL}$ puff volume, 30 s inter-puff break. E-liquids for carryover experiments were chosen based on type of synthetic coolant present (WS-3, WS-23), and based on high, average, or low synthetic coolant and/or nicotine content (see Table 1). After 20 puffs were collected for each experiment, the traps were allowed to thaw and the captured material was taken up in $1 \mathrm{~mL}$ of methanol containing $1 \mathrm{~g} / \mathrm{L}$ of 1,4 dioxane as IS and injected into the GC/FID.

\section{Margin of Exposure calculation for synthetic cooling agents:}

The Margin of Exposure (MOE) is defined as the ratio of the highest test dose that causes no-observed toxicity in animals and the average human dietary intake, and MOE is considered the preferred option for risk assessment of toxic compounds by the Joint FAO/WHO Expert Committee on Food Additives (JECFA) ${ }^{27,28}$. MOEs for non-genotoxic additives exceeding 100 indicate a low health risk for human organ toxicity ${ }^{29,30}$. Additives with MOEs below the safety threshold of 100 are required to be prioritized for risk mitigation. MOEs for WS-3 and WS-23- containing E-liquids were calculated using the following formula, as described previously: ${ }^{18}$

$$
M O E=\frac{\text { NOAEL for synthetic coolant }}{\text { Estimated Exposure Dose (EED) }}
$$

Where NOAEL is the No-Observed-Adverse-Effect-Level, a dose determined as the threshold producing a toxic effect in animal oral toxicity studies. NOAELs for WS-3 and WS-23 have been determined to be $8 \mathrm{mg} / \mathrm{kg}$-bw/day and $5 \mathrm{mg} / \mathrm{kg}$-bw/day, respectively ${ }^{22,23,31}$. Daily Estimated Exposure Doses (EED) were determined from WS-3 and WS-23 concentrations in the E-liquids and their estimated average daily amount consumed. The nicotine amounts in the majority of refill E-liquids ranged between $0.1-1.0 \%$, and user surveys found consumption volumes for such low nicotine E-cigarette liquids to be $9 \mathrm{~mL} /$ day, ranging from 1.7-17.7 mL/day) 19,32,33. To cover a wide range of user behviours, MOEs for these refill E-liquids were calculated for consumption volumes of 1, 3, 5, 10 and $15 \mathrm{~mL} /$ day. For nicotine salt-containing refill liquids (nicotine content $>3 \%$ ), MOEs were calculated for $1,3,5 \mathrm{~mL} /$ day to account for the higher nicotine content. Puffbar E-liquid MOEs were calculated for consumption amounts of half a disposable bar/device, 1 Puffbar/device, and 2 Puffbars/devices. These amounts can be considered equivalent to volumes consumed by light, moderate, and heavy users of $3-5 \%$ 
bioRxiv preprint doi: https://doi org/10.1101/2021.06.09.446946; this version posted June 10, 2021. The copyright holder for this preprint (which was not certified by peer review) is the author/funder, who has granted bioRxiv a license to display the preprint in perpetuity. It is made available under aCC-BY-NC-ND 4.0 International license.

nicotine salt-containing E-cigarettes (Puffbar volume is $1.3 \mathrm{~mL}$ ). For the calculations, a user body weight of $60 \mathrm{~kg}$ was assumed; to convert E-cigarette liquid consumption from volume in $\mathrm{mL} /$ day to $\mathrm{g} /$ day, the densities of propylene glycol and glycerol $\left(1.04\right.$ and $1.26 \mathrm{~g} / \mathrm{cm}^{3}$, respectively) were taken into consideration. 


\section{Results}

Chemical analysis of synthetic cooling agents, nicotine and other flavorants in US-marketed E-cigarette refill liquids, concentrates and their aerosols:

Using our search criteria, $25 \mathrm{E}$-cigarette refill liquids and 1 concentrate from 19 different brands were identified and their contents of synthetic coolants, mint-related compounds and nicotine quantified by GC/MS. Of the analyzed liquids, 21 contained free-base nicotine and 4 nicotine salts. 24 of the 25 E-liquids contained WS-3, with amounts varying from $150 \mu \mathrm{g} / \mathrm{g}$ (Popsicle USA) to 14,650 $\mathrm{\mu g} / \mathrm{g}$ (Arctic Rush) (Table 1). One E-liquid contained WS-23 exclusively (Dillinger), at a concentration of $1,860 \mu \mathrm{g} / \mathrm{g}$ (Table 1). The concentrate contained both WS-3 and WS-23, with concentrations of $8,840 \mu \mathrm{g} / \mathrm{g}$ and 124,060 $\mu \mathrm{g} / \mathrm{g}$, respectively (Table 1).

To verify whether WS-3 and WS-23 carries over into aerosol and reaches the user during E-cigarette use, vaping experiments using an established method were carried out ${ }^{26}$. Carryover was determined for WS-3 with 8 different refill E-liquids $(n=22)$ and carryover rates ranged from $91-109 \%$ (vs. neat E-liquid content), with an overall average carryover of $105 \%$ (s.d. 6.4\%; $n=20$; Table 1). WS-23 was only detected in 1 refill E-liquid, and carryover ranged from $87-105 \%$ (vs. neat E-liquid content), with an overall average carryover of $99 \%$ (s.d. 9.8\%; $n=3$; Table 1).

In addition to WS-3 and WS-23, menthol, menthone, carvone, and nicotine were also quantified. Interestingly, 13 of the 25 refill E-liquids contained varying amounts of menthol, ranging from $330-23,490 \mu \mathrm{g} / \mathrm{g}$ (Table 1). Menthone and Carvone were present in 6 of the 25 E-liquids, ranging from $30-25,450 \mu \mathrm{g} / \mathrm{g}$ for menthone and $10-6830 \mu \mathrm{g} / \mathrm{g}$ for carvone (Table 1). There were also four refill E-liquids that contained menthol, menthone, carvone and WS-3, with total combined amounts for these compounds ranging from 4,940 - 46,150 $\mu \mathrm{g} / \mathrm{g}$ (Table 1). Nicotine concentrations in 20/21 free-base nicotine containing E-liquids were below 1\% (1.41 $9.97 \mathrm{mg} / \mathrm{g}$ ), except for Clove+Cool Hit (17.91 mg/g; Table 1). Nicotine contents in nicotine-salts containing E-liquids ranged from $28.74-44.6 \mathrm{mg} / \mathrm{g}$ (Table 1). Taken together, these results suggest that synthetic coolants are being added to US-marketed E-liquids in a variety of marketed flavors (see Table 1), including in those already containing the "natural" coolant menthol.

Chemical analysis of synthetic cooling agents and menthol in US-marketed disposable E-cigarettes: 
Following the withdrawal of the popular flavored Juul cartridges from the US market, disposable E-cigarette products of the brand "Puffbar" brand have become increasingly popular among US youth and young adults ${ }^{7,8}$. Several Puffbar flavors had 'Ice' in their marketed names, suggesting they may contain synthetic cooling agents. Of the 14 Puffbar flavors analyzed, 13 contained varying amounts of WS-23, ranging from 1,610 - 36,660 $\mu \mathrm{g} / \mathrm{g}$ (Table 2). WS-3 was present in 5/14 flavors with concentrations ranging from 1,880 - 10,770 $\mu \mathrm{g} / \mathrm{g}$ (Table 2). Menthol was present in $7 / 14$ liquids analyzed with amounts ranging from $620-3,680 \mu \mathrm{g} / \mathrm{g}$ (Table 2). All WS-3 and menthol containing Puffbar flavors contained significant amounts of WS-23, with 3/14 flavors containing all three compounds. The total combined concentrations of all three compounds ranged between 8,830 - 48,050 $\mu \mathrm{g} / \mathrm{gram}$ (Table 2). Puffbar liquids containing only WS-3 and WS-23 had a total combined synthetic coolants content ranging from 5,150 - 47,430 $\mu \mathrm{g} / \mathrm{g}$ (Table 2). The nicotine concentrations in the Puffbar E-liquids ranged from $29.4-40.7$ $\mathrm{mg} / \mathrm{g}$.

\section{Margin of Exposure calculations for synthetic coolants in US-marketed refill E-liquids and disposable E-cigarettes:}

Toxicological studies have confirmed significant organ toxicity of orally administered WS-3 and WS-23: JECFA determined NOAEL of 8 and $5 \mathrm{mg} / \mathrm{kg}$-bw, respectively ${ }^{23}$. Some cellular studies observed that WS-23 has clastogenic properties ${ }^{21}$. To assess the risk associated with daily intake of WS-3 and WS-23 from E-cigarette use, we calculated the margin of exposure (MOE) resulting from the daily consumption of a liquid volume range covering low, moderate and high level use scenarios $(1,3,5,10,15 \mathrm{~mL} /$ day for free-base nicotine refill liquids; $1,3,5 \mathrm{~mL} /$ day for nicotine-salts refill liquids; 0.5 , 1 or 2 Puffbars/day for disposables). For organ toxicity, a safety margin MOE of 100 or higher is considered low risk, while MOEs lower than 100 require prioritization by FDA for risk mitigation for a given additive ${ }^{29,30}$.

For the E-liquid with the highest WS-3 concentration (Arctic Rush), MOEs ranged from 32 (1-mL/day) to 2 (15-mL/day; Table 3 and Figure 1), and are thereby significantly lower than the recommended safety margin of 100 . Except for this flavor, MOEs for consumption of $1 \mathrm{ml}$ of all other analyzed refill E-liquids exceeded the threshold of 100 . For consumption volumes of 3 $\mathrm{mL} /$ day, 13/24 WS-3 containing refill E-liquids had a MOE of $\leq 100$, ranging from 87 - 9 . Similarly, 18/24 WS-3 containing refill E-liquids had an MOE of $\leq 100$, ranging from 96 - 6 , for consumption of $5 \mathrm{~mL}$ E-liquid/day. For 10 and $15 \mathrm{~mL} /$ day, MOEs were calculated only for the 20 free-base nicotine containing E-liquids: For $10 \mathrm{ml} / \mathrm{day}, 16 / 20 \mathrm{E}$-liquids yielded an MOE below 100, ranging from 96 - 3, and for $15 \mathrm{ml} /$ day, 19/20 E-liquids yielded an MOE below 100, ranging 
from 96 - 2 (Table 3 and Figure 1). Depending on consumption rates, MOEs for the one WS-23-containing refill E-liquid ranged from 135 - 9, with $\mathrm{MOE}<100$ in all assessed scenarios but $1 \mathrm{~mL} /$ day consumption (Table 3 and Figure 1). The tested concentrate (“Agent Cool”) contained both WS-3 and WS-23. With the vendor recommending to add 1-2 drops of concentrate per pod, we conservatively estimated MOEs for a resulting dilution range of $1-3 \%$. Resulting MOEs for WS-23 when added at 1-3\% to E-liquids were $<100$ at all consumption rates, except for the lowest consumption rate $(1 \mathrm{~mL} /$ day) at $1 \%$ dilution. WS-3 content of the concentrate was approx. 14-fold lower than WS-23, and the resulting MOEs for WS-3 were $>100$ at all consumption and dilution rates. Taken together, these results indicate that users of synthetic coolants flavored E-liquids are exposed to WS-3 and WS-23 levels that can potentially pose a health risk upon long-term use.

Next, we calculated the MOEs for synthetic coolants for daily consumption of Puffbar devices. For the Puffbar flavor with the highest content of both WS-3 and WS-23 (Cool Mint), the MOEs for consumption of 0.5 - 2 devices/day ranged from $57-14$ for WS-3, and $11-2$ for WS-23, values that are significantly lower than the safety margin threshold of 100 (Table 4 and Figure 2). For all other flavors, WS-23 MOEs were similarly $<100$ for all use scenarios, with the exception of Café Latte ( 0.5 device/day) and Menthol ( 0.5 and 1 device/day). MOEs for WS-3 were lower than the safety threshold of 100 at the highest estimated consumption rate (2 devices/day) for all five WS-3 containing Puffbar flavors. MOEs for WS-3 were also <100 for Cucumber and Menthol flavors at 1 pod/day consumption rate. These results indicate that users of Puffbar disposable E-cigarettes are exposed to levels of synthetic coolants that are considered to pose organ toxicity risks, especially from WS-23 exposure. 


\section{Discussion:}

We detected the presence of synthetic coolants (WS-3 and WS-23) in US-marketed E-cigarette refill liquids and almost all tested flavors of the popular disposable E-cigarette brand, Puffbar. Using a relatively low-power Juul-like vaping device, we demonstrate that these coolants can efficiently be aerosolized and carried over to reach user airways. Margins of Exposure (MOE) were calculated to assess the health risks associated with exposure to these coolants from E-cigarette use, a parameter used by FDA and other global regulatory agencies to regulate the safe use of food additives with carcinogenic and organotoxic effects. These calculations suggests that daily intake of WS-3 or WS-23 by E-cigarette users exceed levels that would be considered acceptable for consumption by FDA and European Flavour Association (EFFA).

Natural cooling agents such as menthol provide a cooling sensation by activating coldsensitive trigeminal nerve fibers innervating the upper respiratory tract and oral cavity. These sensory neurons express TRPM8 ion channels, the receptor for menthol that is also activated by cooling ${ }^{34,35}$. Menthol also has counterirritant, antitussive and analgesic properties and inhibits respiratory irritation responses to tobacco smoke and its various irritant constituents through a TRPM8 dependent mechanism in rodent models ${ }^{36,37}$. Menthol, through its actions on TRPM8, attenuated the aversive oral effects of nicotine in mice and increased nicotine intake ${ }^{38}$. The half-maximal concentrations of menthol to activate human TRPM8 is $4 \mu M^{39,40}$. This concentration is known to be exceed after inhalation of menthol cigarette smoke ${ }^{41}$. A menthol concentration of $0.65 \mu \mathrm{M}(16 \mathrm{ppm})$, was sufficient to reduce sensory irritation by cigarette smoke exposure in mice, illustrating the strong counterirritant properties of menthol even at low concentrations ${ }^{36}$. In E-cigarette users, menthol is transferred to the airways with high efficiency, where menthol concentrations per puff are comparable to concentrations in puffs generated from menthol cigarettes ${ }^{9,42}$. Previous analytical studies demonstrated that menthol concentrations in marketed E-liquids range from $2-68,000 \mu \mathrm{g} / \mathrm{mL}(13 \mu \mathrm{M}-435 \mathrm{mM}){ }^{43}$. In the present study, menthol levels in E-cigarette refill liquids and Puffbar devices ranged from 330 23,490 $\mu \mathrm{g} / \mathrm{g}(\sim 2.4-173 \mathrm{mM})$ and $620-3,680 \mu \mathrm{g} / \mathrm{g}(\sim 4.6-27 \mathrm{mM})$, respectively. These levels are sufficient to reduce sensory perception of irritation and harshness elicited by nicotine in humans 44. Similar to menthol, synthetic cooling agents (including WS-3 and WS-23) also activate TRPM8 with increased efficacy (WS-3) and with comparable half-maximal concentrations (WS-3: 2-4 $\mu \mathrm{M}$; WS-23: $44 \mu \mathrm{M})^{39,45,46}$. Several of the refill E-liquids analyzed in this study contained WS-3 at levels comparable to menthol levels in mint- and menthol-flavored E-liquids 
(150-14,650 $\mu \mathrm{g} / \mathrm{g} ; ~ 816 \mu \mathrm{M}-80 \mathrm{mM})$, with some containing synthetic coolants in addition to "natural" cooling agents. The concentrations of WS-3 in several Puffbar E-liquids, up to 1\% $(1,880-10,770 \mu \mathrm{g} / \mathrm{g} ; 10-59 \mathrm{mM})$, are similar to menthol concentrations in liquids of Juul, the market-leading pod E-cigarette system in the US ${ }^{9,42}$. In addition, the majority of the Puffbar Eliquids analyzed in this study contained WS-23 ranging between $1-3.7 \%$ (up to $250 \mathrm{mM}$ ), which is sufficient to mediate TRPM8-dependent counterirritant effects. Carryover of synthetic cooling agents from E-liquids into the vapor was highly efficient, approximating $100 \%$, as previously demonstrated for menthol (Table 1) ${ }^{42}$

Our risk assessment analysis suggests that users of E-cigarettes containing synthetic cooling agents are exposed to amounts of WS-3 and WS-23 that exceed the amounts considered acceptable by regulatory bodies for intake from food. Detected amounts were much higher than the thresholds set by JECFA for human intake of flavor additives of this particular class of chemicals (aliphatic and aromatic amines and amides, FEMA Nos 1594-1601, 1606 and 1613) at $90 \mu \mathrm{g} /$ person/day, either added as individual flavoring or combined total ${ }^{21}$. Even consumption of just $1 \mathrm{~mL}$ of WS-3 containing E-cigarette liquid (150-14650 $\mu \mathrm{g} / \mathrm{g}$ ) results in exposures exceeding JECFA's safety threshold by $\sim 2-180$ fold. Vaping of 1 disposable Puffbar E-cigarette containing synthetic cooling agents would expose a user to amounts of WS-3 $(1,880-10770 \mu \mathrm{g} / \mathrm{g})$ that exceed the threshold of concern by $\sim 29-176$ fold, or $\sim 26-598$ fold for WS-23 (3,940-36660 $\mathrm{\mu g} / \mathrm{g})$. There were 5 Puffbar varieties that contained both WS-3 and WS-23, and when added together, would expose a user vaping 1 Puffbar device to 126 774 fold the recommended amount of amides based on JECFA recommendations. These results strongly suggest that $E$-cigarette users are exposed to synthetic coolant amounts which would be considered unsafe when consumed in food, raising concerns for health risks upon chronic exposure.

\section{Route to route extrapolation significance}

The available chemical toxicity margins for WS-3 and WS-23, such as provided by JECFA, are derived from toxicological studies in animals in which coolants were administered orally ${ }^{21}$. Calculating Margins of Exposure (MOE) for inhalation of a compound based on past oral toxicity studies requires some caution. For human risk assessment and to calculate risk assessment parameters from exposure to these chemicals through various routes, it is routine practice for US and International regulatory agencies (US Environmental Protection Agency, EPA; European Chemical Agency, ECHA; UK's Interdepartmental Group on Health Risks from Chemicals, IGHRC) to employ route-to-route (R2R) extrapolation ${ }^{47,48}$. Regulatory agencies 
agree that the absorption efficiency for chemicals by the respiratory system is higher than the efficiency of the digestive tract and usually, an oral-to-inhalation ratio of 2 is applied for route-toroute extrapolation, reflecting the higher absorption of toxicants following inhalation ${ }^{47-49}$. In this study, R2R extrapolation was not used, however, if applied, the MOE values would be even lower, reflecting an even higher risk associated with inhalation of these two synthetic cooling agents at various daily consumption volumes. This would suggest even greater urgency for regulatory measures mitigating the risk from WS-3 and WS-23 exposures in E-cigarette users.

Recently, an e-vapor product company (RLX technology, China) has conducted a noseonly acute and sub-acute inhalation study for WS-23 (28-day exposure at doses of 19 and 29 $\mathrm{mg} / \mathrm{kg}$-bw/day) ${ }^{24}$. Whole-body plethysmography was conducted after 28 days of repeated exposure to measure various parameters of pulmonary function. Compared to control and solvent groups, mice exposed to WS-23 demonstrated significant changes in various parameters, such as time of expiratory (Te), peak expiratory flow (PEF), relaxation time (RT), minute volume $(\mathrm{MV})$, respiratory rate $(\mathrm{F})$, end-inspiration pause $(\mathrm{EIP})$, end-expiratory pause (EEP). These results indicate that WS-23 may alter pulmonary function of users of WS-23 containing E-cigarettes. However, the study reports no remarkable histopathological changes in either the respiratory organs (nose, throat, trachea and lungs) or other visceral organs (liver, kidney, heart etc.). It has to be noted that the histopathological analysis was not based on a quantitative histopathologic scoring of the organ tissue lesions but based on visual examination of the H\&E stained sections. The absence of histopathological evidence for organ toxicity contradicts prior WS-23 oral toxicity studies in rats that reported kidney lesions and hepatic toxicity starting at $10 \mathrm{mg} / \mathrm{kg}$-bW/day (NOAEL of $5 \mathrm{mg} / \mathrm{kg}$-bW/day) ${ }^{21,22}$. The discrepancy between these observations could be due to the different routes of exposure (oral vs. inhalation), or more importantly, may have resulted from the different exposure durations (14weeks oral dosing vs. 4-weeks inhalational exposure).

In vitro genotoxicity studies of WS-23 in mammalian cells showed evidence for clastogenicity ${ }^{21}$. Clastogenicity was observed only in the presence of metabolic activation, indicating that the effect is mediated by the formation of a reactive metabolite. Due to the increased exposure to WS-23 from use of E-cigarettes, it is imperative that more studies are conducted to understand the mechanisms of their metabolism and further identify WS-23's reactive clastogenic metabolites.

Previous toxicological studies have examined the toxicological effects of synthetic cooling agents, including WS-3 and WS-23, in isolation, and not in mixtures. As demonstrated in 
this study, refill E-cigarette liquids and popular disposable E-cigarettes contain mixtures of natural and synthetic cooling agents. Inhalation toxicity studies are required to examine the effects of acute, sub-acute and chronic exposures to mixtures of these chemicals and marketed E-cigarettes that contain such mixtures. Another limitation in assessing the risk associated from use of these E-cigarettes is the rapidly evolving product variety and the dynamic nature of their composition. The products analyzed in this study were purchased in the last 1-2 years. More recent marketed products may contain different compositions. Hence, a continuous monitoring of new E-cigarette products by determining their chemical compositions for presence of potentially toxic flavorant levels is critical for both regulatory and risk assessment purposes.

In Puffbar disposable products, synthetic cooling agents were not only found in mint/menthol-flavored, or "cool"- or "ice"-labelled E-liquids, but in almost all products tested (13/14), suggesting that a cooling effect is preferred by consumers. Cooling agents were added to fruit-flavored E-liquids named "Orange Ice" and "Blueberry Ice", but also "Strawberry Banana" and "Lychee", without the "Ice" label, and in "Cucumber" and "OMG" flavors. This illustrates the utility of odorless synthetic cooling agents to add a cooling effect to flavors that likely would not be favored by users when combined with menthol, due to the incompatible minty odor the "natural" coolant menthol would add. Synthetic cooling agents may allow tolerance of more intense flavor combinations that would otherwise be irritating.

The fact that synthetic coolants are odorless also raises another important question: Legislation such as the FSPTCA or the European Tobacco Product Directive (TPD) 1,2,50,51 banned "characterizing" flavorants from combustible tobacco products (with exemption for menthol in the US), yet is unclear how synthetic coolants lacking a characterizing flavor would be treated. A replacement of the cooling compound menthol (with a minty characterizing flavor) with a synthetic coolants (lacking characterizing flavor) could be a strategy to circumvent a a menthol ban. Policy makers should consider this when implementing menthol bans, such as both Canada and Germany have done in respective regulations that either maintain a positive list of compounds permitted as additives in tobacco products (Canada), or specifically ban a whole class of compounds, including all natural and synthetic derivatives of menthol and other cooling agents (Germany) ${ }^{52,53}$ 


\section{Conclusions:}

Synthetic cooling agents are added to US-marketed E-cigarettes in a wide range of amounts that are comparable and relative to menthol amounts in flavored E-cigarettes. Synthetic coolants were found not only in mint- and menthol-flavored products, but also in fruit-, dessertand sweet-flavored E-cigarettes. These coolants are added to refill liquids, E-cigarette liquid diluents and popular disposable E-cigarettes such as Puffbar, at levels that pose potential health risks to users, thereby requiring for these products to be prioritized for risk mitigation measures. 


\section{Funding:}

This work was supported by the National Institute on Drug Abuse (NIDA) of the National Institutes of Health (NIH) and the Center for Tobacco Products of the US Food and Drug Administration (FDA) (P50DA036151 and U54DA036151; Yale Tobacco Center of Regulatory

Science, TCORS); and National Institute of Environmental Health Sciences (NIEHS) (R01ES029435 to Dr. Sven-Eric Jordt).

\section{Declaration of Interests:}

The funding organization had no role in the design and conduct of the study; the collection, management, analysis, and interpretation of the data; the preparation, review, or approval of the manuscript; nor in the decision to submit the manuscript for publication. The content is solely the responsibility of the authors and does not necessarily represent the views of National institutes of Health (NIH) or the Food and Drug Administration (FDA). Dr. Jordt reports receiving personal fees from Hydra Biosciences LLC and Sanofi S.A. and nonfinancial support from GlaxoSmithKline Pharmaceuticals outside the submitted work. No other financial disclosures were reported by the authors of this paper.

Author contributions were as follows: SVJ, HCE and SEJ conceptualized and designed the study; DGT, LD, and HCE acquired and analyzed the chemical analytical data; SVJ analyzed and interpreted the data for risk analysis calculations; SVJ, SEJ and HCE drafted the manuscript; SVJ, HCE, PTA, JBZ, and SEJ provided supervision; JBZ critically revised the manuscript for important intellectual content. 
1. FDA Center for Tobacco Products $\mathrm{C}$ for T. Family Smoking Prevention and Tobacco Control Act Table of Contents. FDA. Published online March 19, 2019. Accessed June 7, 2021. https://www.fda.gov/tobacco-products/rules-regulations-and-guidance/family-smokingprevention-and-tobacco-control-act-table-contents

2. FDA Center for Tobacco Products. Family Smoking Prevention and Tobacco Control Act - An Overview. FDA. Published online June 3, 2020. Accessed June 7, 2021. https://www.fda.gov/tobacco-products/rules-regulations-and-guidance/family-smokingprevention-and-tobacco-control-act-overview

3. FDA Center for Tobacco Products. Menthol and Other Flavors in Tobacco Products. FDA. Published online April 28, 2021. Accessed May 14, 2021. https://www.fda.gov/tobacco-products/productsingredients-components/menthol-and-other-flavors-tobacco-products

4. Villanti AC, Mowery PD, Delnevo CD, Niaura RS, Abrams DB, Giovino GA. Changes in the prevalence and correlates of menthol cigarette use in the USA, 2004-2014. Tobacco Control. 2016;25(Suppl 2):ii14-ii20. doi:10.1136/tobaccocontrol-2016-053329

5. Food and Drug Administration. FDA Commits to Evidence-Based Actions Aimed at Saving Lives and Preventing Future Generations of Smokers. FDA. Published April 30, 2021. Accessed May 10, 2021. https://www.fda.gov/news-events/press-announcements/fda-commits-evidence-based-actionsaimed-saving-lives-and-preventing-future-generations-smokers

6. Commissioner $\mathrm{O}$ of the. FDA finalizes enforcement policy on unauthorized flavored cartridge-based e-cigarettes that appeal to children, including fruit and mint. FDA. Published March 24, 2020. Accessed May 14, 2021. https://www.fda.gov/news-events/press-announcements/fda-finalizesenforcement-policy-unauthorized-flavored-cartridge-based-e-cigarettes-appeal-children

7. Wang TW. E-cigarette Use Among Middle and High School Students - United States, 2020. MMWR Morb Mortal Wkly Rep. 2020;69. doi:10.15585/mmwr.mm6937e1

8. Ali FRM. E-cigarette Unit Sales, by Product and Flavor Type - United States, 2014-2020. MMWR Morb Mortal Wkly Rep. 2020;69. doi:10.15585/mmwr.mm6937e2

9. Erythropel HC, Anastas PT, Krishnan-Sarin S, O'Malley SS, Jordt SE, Zimmerman JB. Differences in flavourant levels and synthetic coolant use between USA, EU and Canadian Juul products. Tob Control. Published online April 27, 2020. doi:10.1136/tobaccocontrol-2019-055500

10. Leffingwell JC. Cool without Menthol \& Cooler than Menthol and Cooling Compounds as Insect Repellents. Cool without Menthol \& Cooler than Menthol. Published June 8, 2018. Accessed May 14, 2021. http://www.leffingwell.com/cooler_than_menthol.htm

11. Leffingwell JC, Rowsell D. Wilkinson Sword Cooling Compounds: From the Beginnning to Now. Perfumer \& Flavorist. 2014;39(3):34-43.

12. Leffingwell JC. WILKINSON-SWORD “'CWM””. Published online March 5, 1975. https://www.industrydocuments.ucsf.edu/docs/tkjn0089 
13. Newman F. Memorandum From Philip Morris In-House Counsel (Newman) To Philip Morris InHouse Counsel (Holtzman) Providing Legal Advice And Analysis Regarding Content Of Draft Press Release For New Product Introduction; Northwind Comments On 3rd Tier Inquires. Published online March 14, 1981. Accessed May 24, 2021. https://www.industrydocuments.ucsf.edu/docs/kgxy0101

14. Reger L; M J; Hahn, H; Hahn, J. Analysis of Menthol, Menthol-Like, and Other Tobacco Flavoring Compounds in Cigarettes and in Electrically Heated Tobacco Products. Beiträge zur Tabakforschung International Contributions to Tobacco Research. 2018;28(2):93-102. doi:10.2478/cttr-2018-0010

15. Jabba SV, Jordt SE. Turbocharged Juul device challenges European tobacco regulators. Eur Respir J. 2020;56(2). doi:10.1183/13993003.02430-2020

16. Liquid Nicotine Wholesalers. Koolada 10\% PG (TFA). Liquid Nicotine Wholesalers. Accessed June 8, 2021. https://liquidnicotinewholesalers.com/flavor-apprentice-koolada-10-pg.html

17. Koolada Powder / Menthyl methyl lactate | E-Cigarette Forum. Accessed May 25, 2021. https://www.e-cigarette-forum.com/threads/koolada-powder-menthyl-methyl-lactate.485686/

18. Jabba SV, Jordt SE. Risk Analysis for the Carcinogen Pulegone in Mint- and Menthol-Flavored eCigarettes and Smokeless Tobacco Products. JAMA Intern Med. Published online September 16, 2019. doi:10.1001/jamainternmed.2019.3649

19. Jabba SV, Jordt SE. Estimating Fluid Consumption Volumes in Electronic Cigarette Use-Reply. JAMA Intern Med. 2020;180(3):468-469. doi:10.1001/jamainternmed.2019.6630

20. Hallagan J. The Safety Assessment and Regulatory Authority to Use Flavors - Focus on E-Cigarettes. Published online March 3, 2015. Accessed June 8, 2021.

https://www.femaflavor.org/sites/default/files/FEMAGRAS_Ecig_March_3_2015.pdf

21. Joint Expert Committee on Food Additives, ed. Evaluation of Certain Food Additives: Sixty-Ninth Report of the Joint FAO/WHO Expert Committee on Food Additives ; [Rome, 17 - 26 June 2008].; 2009. http://www.inchem.org/documents/jecfa/jecmono/v952je01.pdf

22. Cheng M. A Subchronic Oral Toxicity Study of T0332.04 in Rats. Unpublished Report to the Flavor Manufacturers Association. Submitted to WHO by the Flavor and Extract Manufacturers Association of the United States, Washington DC, USA. Hazleton Laboratories, Madison, Wisconsin, USA.; 1982.

23. Joint FAO/WHO Expert Committee on Food Additives. Meeting (65th : 2005: Geneva Switzerland), International Program on Chemical Safety. Safety Evaluation of Certain Food Additives. World Health Organization, International Programme on Chemical Safety; 2006.

24. Wu Z-H, Liu Y-S, Li X-D, et al. Acute and subacute inhalation toxicity assessment of WS-23 in Sprague-Dawley rats. J Appl Toxicol. Published online March 23, 2021. doi:10.1002/jat.4166 
25. Erythropel HC, Jabba SV, DeWinter TM, et al. Formation of flavorant-propylene Glycol Adducts With Novel Toxicological Properties in Chemically Unstable E-Cigarette Liquids. Nicotine Tob Res. 2019;21(9):1248-1258. doi:10.1093/ntr/nty192

26. Rosbrook K, Erythropel HC, DeWinter TM, et al. The effect of sucralose on flavor sweetness in electronic cigarettes varies between delivery devices. PLoS One. 2017;12(10):e0185334. doi:10.1371/journal.pone.0185334

27. WHO/IPC. Environmental Health Criteria 239: Principles for Modellingdose-Response for the Risk Assessment of Chemicals. World Health Organization https://apps.who.int/iris/bitstream/handle/10665/44065/WHO_EHC_240_8_eng_Chapter5.pdf?s equence $=8$

28. Benford D, Bolger PM, Carthew $\mathrm{P}$, et al. Application of the Margin of Exposure (MOE) approach to substances in food that are genotoxic and carcinogenic. Food and Chemical Toxicology. 2010;48:S2-S24. doi:10.1016/j.fct.2009.11.003

29. National Research Council (U.S.), ed. Risk Assessment in the Federal Government: Managing the Process. National Academy Press; 1983.

30. Scientific Committee. Use of the 'Margin of Exposure' (MOE) Approach for Deriving Risk-Based Action Limits for Carcinogens Unintentionally Present in Food.; 2019. Accessed June 1, 2021. https://www.favv-afsca.be/scientificcommittee/opinions/2019/_documents/Opinion152019_SciCom2018-12_MOEactionlimits.pdf

31. Miyata K. Summary of 28-Day Repeated Dose Oral Toxicity Study of WS-3. Unpublished Report to the Flavor Manufacturers Association. Submitted to WHO by the Flavor and Extract Manufacturers Association of the United States, Washington DC, USA.; 1995.

32. Chaumont M, de Becker B, Zaher W, et al. Differential Effects of E-Cigarette on Microvascular Endothelial Function, Arterial Stiffness and Oxidative Stress: A Randomized Crossover Trial. Sci Rep. 2018;8(1):10378. doi:10.1038/s41598-018-28723-0

33. Smets J, Baeyens F, Chaumont M, Adriaens K, Van Gucht D. When Less is More: Vaping LowNicotine vs. High-Nicotine E-Liquid is Compensated by Increased Wattage and Higher Liquid Consumption. Int J Environ Res Public Health. 2019;16(5). doi:10.3390/ijerph16050723

34. McKemy DD, Neuhausser WM, Julius D. Identification of a cold receptor reveals a general role for TRP channels in thermosensation. Nature. 2002;416(6876):52-58. doi:10.1038/nature719

35. Peier AM, Moqrich A, Hergarden AC, et al. A TRP channel that senses cold stimuli and menthol. Cell. 2002;108(5):705-715. doi:10.1016/s0092-8674(02)00652-9

36. Willis DN, Liu B, Ha MA, Jordt S-E, Morris JB. Menthol attenuates respiratory irritation responses to multiple cigarette smoke irritants. FASEB J. 2011;25(12):4434-4444. doi:10.1096/fj.11-188383

37. Ha MA, Smith GJ, Cichocki JA, et al. Menthol attenuates respiratory irritation and elevates blood cotinine in cigarette smoke exposed mice. PLoS One. 2015;10(2):e0117128. doi:10.1371/journal.pone.0117128 
38. Fan L, Balakrishna S, Jabba SV, et al. Menthol decreases oral nicotine aversion in C57BL/6 mice through a TRPM8-dependent mechanism. Tob Control. 2016;25(Suppl 2):ii50-ii54.

doi:10.1136/tobaccocontrol-2016-053209

39. Behrendt H-J, Germann T, Gillen C, Hatt H, Jostock R. Characterization of the mouse cold-menthol receptor TRPM8 and vanilloid receptor type-1 VR1 using a fluorometric imaging plate reader (FLIPR) assay. Br J Pharmacol. 2004;141(4):737-745. doi:10.1038/sj.bjp.0705652

40. Klein AH, lodi Carstens M, McCluskey TS, et al. Novel menthol-derived cooling compounds activate primary and second-order trigeminal sensory neurons and modulate lingual thermosensitivity. Chem Senses. 2011;36(7):649-658. doi:10.1093/chemse/bjr029

41. Tobacco Products Scientific Advisory Committee. Menthol Cigarettes and Public Health: Review of the Scientific Evidence and Recommendations. US Department of Health and Human Services, Food and Drug Administration; 2011:1-252. Accessed April 27, 2021. https://wayback.archiveit.org/7993/20170405201731/https:/www.fda.gov/downloads/AdvisoryCommittees/Committees MeetingMaterials/TobaccoProductsScientificAdvisoryCommittee/UCM269697.pdf

42. Erythropel HC, Davis LM, de Winter TM, et al. Flavorant-Solvent Reaction Products and Menthol in JUUL E-Cigarettes and Aerosol. Am J Prev Med. 2019;57(3):425-427. doi:10.1016/j.amepre.2019.04.004

43. Omaiye EE, McWhirter KJ, Luo W, Tierney PA, Pankow JF, Talbot P. High concentrations of flavor chemicals are present in electronic cigarette refill fluids. Scientific Reports. 2019;9(1):2468. doi:10.1038/s41598-019-39550-2

44. Rosbrook K, Green BG. Sensory Effects of Menthol and Nicotine in an E-Cigarette. Nicotine \& Tobacco Research. 2016;18(7):1588-1595. doi:10.1093/ntr/ntw019

45. Sherkheli MA, Vogt-Eisele AK, Bura D, Beltrán Márques LR, Gisselmann G, Hatt H. Characterization of selective TRPM8 ligands and their structure activity response (S.A.R) relationship. J Pharm Pharm Sci. 2010;13(2):242-253. doi:10.18433/j3n88n

46. Johnson S, Tian M, Sheldon G, Dowd E. Trigeminal Receptor Study of High-Intensity Cooling Agents. J Agric Food Chem. 2018;66(10):2319-2323. doi:10.1021/acs.jafc.6b04838

47. European Chemicals Agency (ECHA). Guidance on Information Requirements and Chemical Safety Assessment Chapter R.8: Characterisation of Dose [Concentration]-Response for Human Health. European Chemicals Agency; 2012. https://echa.europa.eu/documents/10162/13632/information_requirements_r8_en.pdf

48. The Interdepartmental Group on Health Risks from Chemicals (IGHRC). Guidelines on Route-toRoute Extrapolation of Toxicity Data When Assessing Health Risks of Chemicals. Cranfield University; 2006. http://www.iehconsulting.co.uk/IEH_Consulting/IEHCPubs/IGHRC/cr12.pdf

49. Schröder K, Escher SE, Hoffmann-Dörr S, Kühne R, Simetska N, Mangelsdorf I. Evaluation of routeto-route extrapolation factors based on assessment of repeated dose toxicity studies compiled in the database RepDose ${ }^{\circledR}$. Toxicol Lett. 2016;261:32-40. doi:10.1016/j.toxlet.2016.08.013 
50. European Union. Tobacco Products Directive (2014/40/EU). Public Health - European Commission. Published November 25, 2016. Accessed June 8, 2021.

https://ec.europa.eu/health/tobacco/products_en

51. European Union. Revision of the Tobacco Products Directive. Public Health - European Commission. Published November 25, 2016. Accessed June 8, 2021.

https://ec.europa.eu/health/tobacco/products/revision_en

52. TabakerzV - Verordnung über Tabakerzeugnisse und verwandte Erzeugnisse. Accessed June 8, 2021. https://www.gesetze-im-internet.de/tabakerzv/BJNR098010016.html

53. Health Canada. Order Amending the Schedule to the Tobacco Act (Menthol). Published August 2, 2017. Accessed June 8, 2021. https://www.canada.ca/en/health-canada/programs/consultationchanges-tobacco-act-address-menthol/order-amending-schedule-tobacco-act-menthol.html 


\section{Figure Legends}

Figure 1: Margins of Exposure (MOE) for synthetic cooling agents from E-Cigarette refill liquids and coolant concentrate. MOEs are plotted for representative WS-3 (left) and WS-23 (right) -containing E-liquids and diluents with high, intermediate and low coolant concentrations, for daily consumption of 1, 3, 5, 10 and $15 \mathrm{ml}$ E-liquid. No Observed Adverse Effect Levels (NOAEL) determined by JECFA in animal studies of organ toxicity upon oral administration were used for MOE calculations. A MOE of $<100$ (dashed line) signals a safety concern and requires regulatory mitigation. For WS-23 concentrate (Agent Cool, TBD Liquids), MOEs were calculated for dilutions within the range of manufacturer-recommendations to 1 and $3 \%$. MOEs of the oral average daily intake of US consumers (US-OADI) determined by JECFA are displayed for comparison.

Figure 2: Margins of Exposure (MOE) for synthetic cooling agents from Puffbar-branded disposable E-cigarettes. MOEs are plotted for exposures from Puffbar devices with flavored E-liquids containing both WS-3 and WS-23, at high (Cool mint), intermediate (Blueberry ice) or low (Menthol) concentrations, separated for each coolant (left: WS-3, right: WS-23), calculated for daily consumption of $1 / 2$ Puffbar $(0.65 \mathrm{~mL}), 1$ Puffbar $(1.3 \mathrm{~mL})$ and 2 bars $(2.6 \mathrm{~mL})$. JECFAdetermined NOAEL values were used for MOE calculations. MOEs of the oral average daily intake of US consumers (US-OADI) determined by JECFA are displayed for comparison. 


\begin{tabular}{|c|c|c|c|c|c|c|c|c|c|}
\hline & \multirow[b]{2}{*}{$\begin{array}{l}\text { E-cigarette Flavor } \\
\text { (Manufacturer) }\end{array}$} & \multicolumn{5}{|c|}{ Flavor Concentration \pm s.d. $(\mu \mathrm{g} / \mathrm{g})$} & \multirow{2}{*}{$\begin{array}{c}\text { Nicotine } \\
\text { concentration } \\
\pm \text { s.d. }(\mathrm{mg} / \mathrm{g})\end{array}$} & \multirow{2}{*}{$\begin{array}{l}\text { PG/VG } \\
\text { ratio }\end{array}$} & \multirow{2}{*}{$\begin{array}{c}\text { Synthetic } \\
\text { coolant } \\
\text { carryover } \\
\pm \text { s.d. (\%) }\end{array}$} \\
\hline & & WS-3 & WS-23 & Menthol & Methone & Carvone & & & \\
\hline 1 & Arctic Rush (Central Vapors) & $14650 \pm 230$ & & & & & $9.2 \pm 0.09$ & $50 / 50$ & $106 \pm 4$ \\
\hline 2 & Frzn Mango (BLVK) & $2450 \pm 00$ & & $3640 \pm 10$ & & & $5.08 \pm 0.03$ & $30 / 70$ & \\
\hline 3 & $\begin{array}{l}\text { Nuclear White Menthol (Vapor } \\
\text { HQ) }\end{array}$ & $2440 \pm 10$ & & $23490 \pm 130$ & $310 \pm 20$ & $190 \pm 70$ & $9.88 \pm 0.02$ & $50 / 50$ & $104 \pm 4$ \\
\hline 4 & Rich Girl (Stunna) & $2260 \pm 30$ & & & & & $3.31 \pm 0.06$ & $70 / 30$ & $107 \pm 11$ \\
\hline 5 & Frozen Berries (Shinjin Vapor) & $2220 \pm 20$ & & $2320 \pm 20$ & & & $3.36 \pm 0.05$ & $30 / 70$ & \\
\hline 6 & Frozen Limeade (Shinjin Vapor) & $1540 \pm 20$ & & $3470 \pm 50$ & & & $3.38 \pm 0.04$ & $30 / 70$ & \\
\hline 7 & Cool Lime (Chill) & $2110 \pm 60$ & & & & & $1.63 \pm 0.05$ & $30 / 70$ & \\
\hline 8 & Tropicool (Chill) & $2040 \pm 40$ & & & & & $3.02 \pm 0.07$ & $30 / 70$ & $91^{\mathrm{a}}$ \\
\hline 9 & Kool Cali (Chill) & $1690 \pm 20$ & & & & & $4.20 \pm 0.06$ & $40 / 60$ & \\
\hline 10 & Sakura 3 mg Nic (Sugoi) & $1090 \pm 20$ & & $910 \pm 10$ & & & $2.32 \pm 0.03$ & $30 / 70$ & $105 \pm 2$ \\
\hline 11 & Coconut Ice (EC Blend) & $2240 \pm 10$ & & & & & $1.41 \pm 0.02$ & $60 / 40$ & \\
\hline 12 & Clove + Cool Hit (EC Blend) & $1600 \pm 20$ & & & & & $17.91 \pm 0.23$ & $50 / 50$ & \\
\hline 13 & Popsicle USA (EC Blend) & $150 \pm 10$ & & & & $10 \pm 1$ & & $60 / 40$ & \\
\hline 14 & Frozen (FJ's ) & $1550 \pm 50$ & & & & & & $30 / 70$ & \\
\hline 15 & $\begin{array}{l}\text { Wintergreen Menthol } \\
\text { (VaporHQ) }\end{array}$ & $870 \pm 20$ & & $4850 \pm 30$ & & & $9.72 \pm 0.08$ & $50 / 50$ & \\
\hline 16 & Icy Menthol (Vista Vapors) & $560 \pm 10$ & & $9240 \pm 90$ & $1320 \pm 50$ & $2890 \pm 10$ & $9.80 \pm 0.02$ & $50 / 50$ & \\
\hline 17 & Ice Dragon (ELD Flavors) & $410 \pm 30$ & & & & & $2.75 \pm 0.01$ & $20 / 80$ & \\
\hline 18 & Wintermint (Gothic Vapor) & $330 \pm 50$ & & $1110 \pm 190$ & & $510 \pm 10$ & $9.03 \pm 0.84$ & $50 / 50$ & \\
\hline 19 & Climate Change (What Juice) & $290 \pm 10$ & & $330 \pm 10$ & & & $9.48 \pm 0.12$ & $30 / 70$ & \\
\hline 20 & Arctic (Vista Select) & $280 \pm 20$ & & $3470 \pm 10$ & $30 \pm 10$ & $930 \pm 70$ & $6.59 \pm 0.06$ & $30 / 70$ & \\
\hline 21 & Dillinger (NastyJuice X Kilo) & & $1860 \pm 40$ & & $280 \pm 10$ & & $4.29 \pm 0.07$ & $30 / 70$ & $99 \pm 10$ \\
\hline 22 & Kool Peach (Salty Man) & $990 \pm 20$ & & & & & $46.4 \pm 1.09$ & $40 / 60$ & $109 \pm 1$ \\
\hline 23 & Sakura Nic Salts 35 mg (Sugoi) & $1170 \pm 30$ & & $1170 \pm 20$ & & & $28.74 \pm 0.43$ & $50 / 50$ & \\
\hline 24 & Sakura Nic Salts 50 mg (Sugoi) & $1140 \pm 60$ & & $1140 \pm 90$ & $14110 \pm 670$ & & $39.19 \pm 2.20$ & $50 / 50$ & $97^{\mathrm{a}}$ \\
\hline 25 & $\begin{array}{l}\text { Unicorn Nicotine Salt } \\
\text { Spearmint (BLVK) }\end{array}$ & $2950 \pm 20$ & & $10920 \pm 160$ & $25450 \pm 600$ & $6830 \pm 40$ & $41.36 \pm 0.33$ & $40 / 60$ & $107 \pm 8$ \\
\hline 26 & $\begin{array}{l}\text { Agent Cool Super Concentrate } \\
\text { (TBD Liquids) }\end{array}$ & $8840 \pm 130$ & $124060 \pm 720$ & & & & & & \\
\hline
\end{tabular}


Table 1: Chemical concentrations for menthol, menthone, carvone, synthetic cooling agents (WS-3 and WS-23) and solvent chemicals in USmarketed E-cigarette refill liquids. Carryover rates for synthetic coolants are provided for select refill liquids. ${ }^{a}$ single experiment. 


\begin{tabular}{|c|l|c|c|c|c|}
\hline & \multicolumn{1}{|c|}{$\begin{array}{c}\text { Puffbar } \\
\text { flavors }\end{array}$} & \multicolumn{2}{c|}{ Flavor Concentration \pm s.d. ( $\mu$ g/g) } & \multirow{2}{*}{$\begin{array}{c}\text { Nicotine } \pm \text { s.d. } \\
\text { (mg/g) }\end{array}$} \\
\hline \multirow{2}{*}{1} & & WS-3 & WS-23 & Menthol & \\
\cline { 2 - 5 } & Cool Mint & $10770 \pm 210$ & $36660 \pm 530$ & $620 \pm 50$ & $32.79 \pm 0.38$ \\
\hline 2 & Café Latte & & $2300 \pm 30$ & $1500 \pm 50$ & $36.56 \pm 0.30$ \\
\hline 3 & Orange Ice & $1750 \pm 20$ & $22950 \pm 450$ & & $37.61 \pm 0.76$ \\
\hline 4 & Pomegranate & & & & $29.37 \pm 0.47$ \\
\hline 5 & Lush Ice & & $25830 \pm 450$ & $2250 \pm 190$ & $32.26 \pm 0.53$ \\
\hline 6 & Melon Ice & & $8810 \pm 60$ & & $32.81 \pm 0.29$ \\
\hline 7 & Cucumber & $3770 \pm 20$ & $3940 \pm 10$ & & $31.67 \pm 0.15$ \\
\hline 8 & Lychee & & $26240 \pm 240$ & & $33.22 \pm 0.27$ \\
\hline 9 & Menthol & $3540 \pm 30$ & $1610 \pm 1950$ & $3680 \pm 550$ & $33.25 \pm 0.22$ \\
\hline 10 & Blueberry Ice & $1880 \pm 20$ & $14120 \pm 210$ & $2300 \pm 40$ & $32.71 \pm 0.45$ \\
\hline \multirow{2}{*}{11} & Strawberry & & $5420 \pm 90$ & & $32.12 \pm 0.52$ \\
\hline 12 & OManana & & $7390 \pm 330$ & $1330 \pm 40$ & $34.01 \pm 1.35$ \\
\hline 13 & Peach Ice & & $11540 \pm 270$ & & $33.11 \pm 0.63$ \\
\hline 14 & Banana Ice & & $13110 \pm 50$ & $2040 \pm 110$ & $40.66 \pm 0.22$ \\
\hline
\end{tabular}

WS-3

WS-23

Menthol

Table 2: Chemical concentrations for synthetic cooling agents (WS-3 and WS-23), menthol and menthol in various flavors of US-marketed disposable E-cigarettes, Puffbars. 
bioRxiv preprint doi: https://doi.org/10.1101/2021.06.09.446946; this version posted June 10, 2021. The copyright holder for this preprint

(which was not certified by peer review) is the author/funder, who has granted bioRxiv a license to display the preprint in perpetuity. It is made available under aCC-BY-NC-ND 4.0 International license.

\begin{tabular}{|c|l|c|c|c|c|c|c|c|}
\hline \multirow{2}{*}{} & \multirow{2}{*}{ E-cigarette Flavor (Manufacturer) } & \multicolumn{3}{|c|}{$\begin{array}{c}\text { Flavor Concentration } \\
(\mathbf{\mu g} / \mathbf{g})\end{array}$} & \multicolumn{3}{|c|}{ MOE for Daily E-Liquid (mL/day) } \\
Amount-Consumed
\end{tabular}

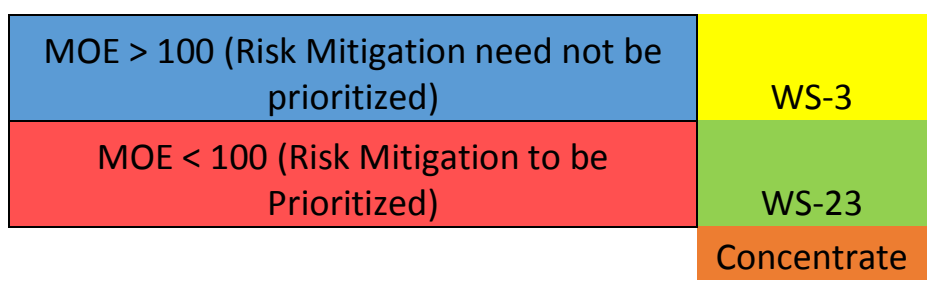

Table 3: Predicted MOE for Synthetic Cooling Agents Containing US-marketed E-Cigarette Liquids Used in Vape Tanks and Vape Mod Devices. 


\begin{tabular}{|c|c|c|c|c|c|c|c|c|c|}
\hline & \multirow[t]{2}{*}{$\begin{array}{c}\text { Puff Bars } \\
\text { Flavors }\end{array}$} & \multicolumn{2}{|c|}{$\begin{array}{c}\text { Flavor } \\
\text { Concentration } \\
(\mu \mathrm{g} / \mathrm{g})\end{array}$} & \multicolumn{3}{|c|}{$\begin{array}{l}\text { WS-3 MOE for Daily } \\
\text { E-Liquid Amount- } \\
\text { Consumed (pods/day) }\end{array}$} & \multicolumn{3}{|c|}{$\begin{array}{l}\text { WS-23 MOE for Daily } \\
\text { E-Liquid Amount- } \\
\text { Consumed (pods/day) }\end{array}$} \\
\hline & & WS-3 & WS-23 & 1/2 Pod & 1 Pod & 2 Pods & $\begin{array}{l}1 / 2 \\
\text { Pod }\end{array}$ & 1 Pod & 2 Pods \\
\hline 1 & Cool Mint & 10770 & 36660 & 57 & 29 & 14 & 11 & 5 & 3 \\
\hline 2 & Café Latte & & 2300 & & & & 168 & 84 & 42 \\
\hline 3 & Orange Ice & 1750 & 22950 & 353 & 177 & 88 & 17 & 8 & 4 \\
\hline 4 & Pomegranate & & & & & & & & \\
\hline 5 & Lush Ice & & 25830 & & & & 15 & 7 & 4 \\
\hline 6 & Melon Ice & & 8810 & & & & 44 & 22 & 11 \\
\hline 7 & Cucumber & 3770 & 3940 & 164 & 82 & 41 & 98 & 49 & 25 \\
\hline 8 & Lychee & & 26240 & & & & 15 & 7 & 4 \\
\hline 9 & Menthol & 3540 & 1610 & 175 & 87 & 44 & 240 & 120 & 60 \\
\hline 10 & Blueberry lce & 1880 & 14120 & 329 & 164 & 82 & 27 & 14 & 7 \\
\hline 11 & $\begin{array}{l}\text { Strawberry } \\
\text { Banana }\end{array}$ & & 5420 & & & & 71 & 36 & 18 \\
\hline 12 & OMG & & 7390 & & & & 52 & 26 & 13 \\
\hline 13 & Peach Ice & & 11540 & & & & 33 & 17 & 8 \\
\hline 14 & Banana Ice & & 13110 & & & & 29 & 15 & 7 \\
\hline
\end{tabular}

\section{MOE > 100}

(Risk

Mitigation need

not be

prioritized)

MOE < 100

(Risk

Mitigation to be

Prioritized)
WS-3

WS-23

Table 4: Predicted MOE for Synthetic Cooling Agents Containing Popular Disposable E-Cigarettes, Puffbar. 


\section{Figure 1}

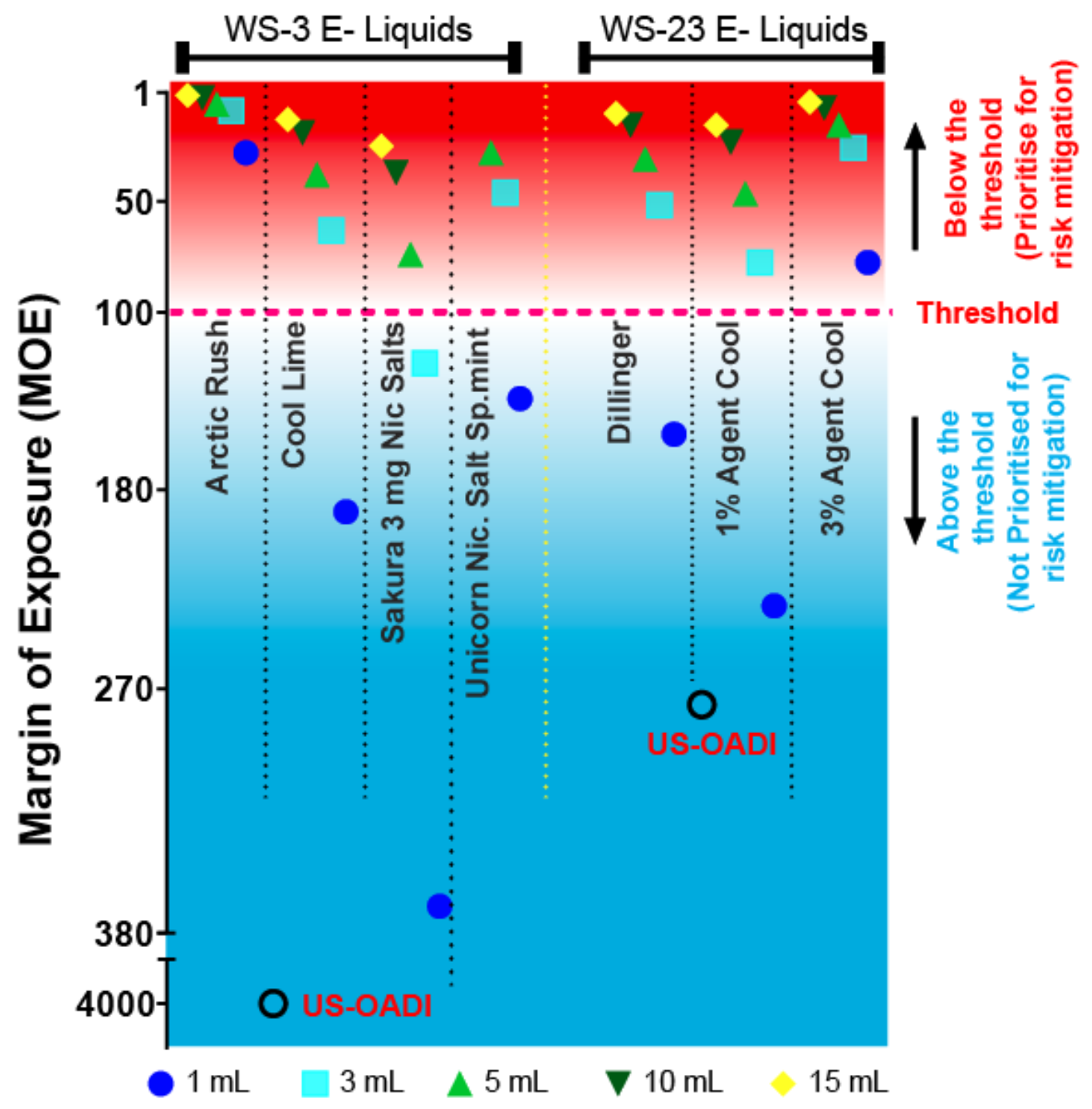




\section{Figure 2}

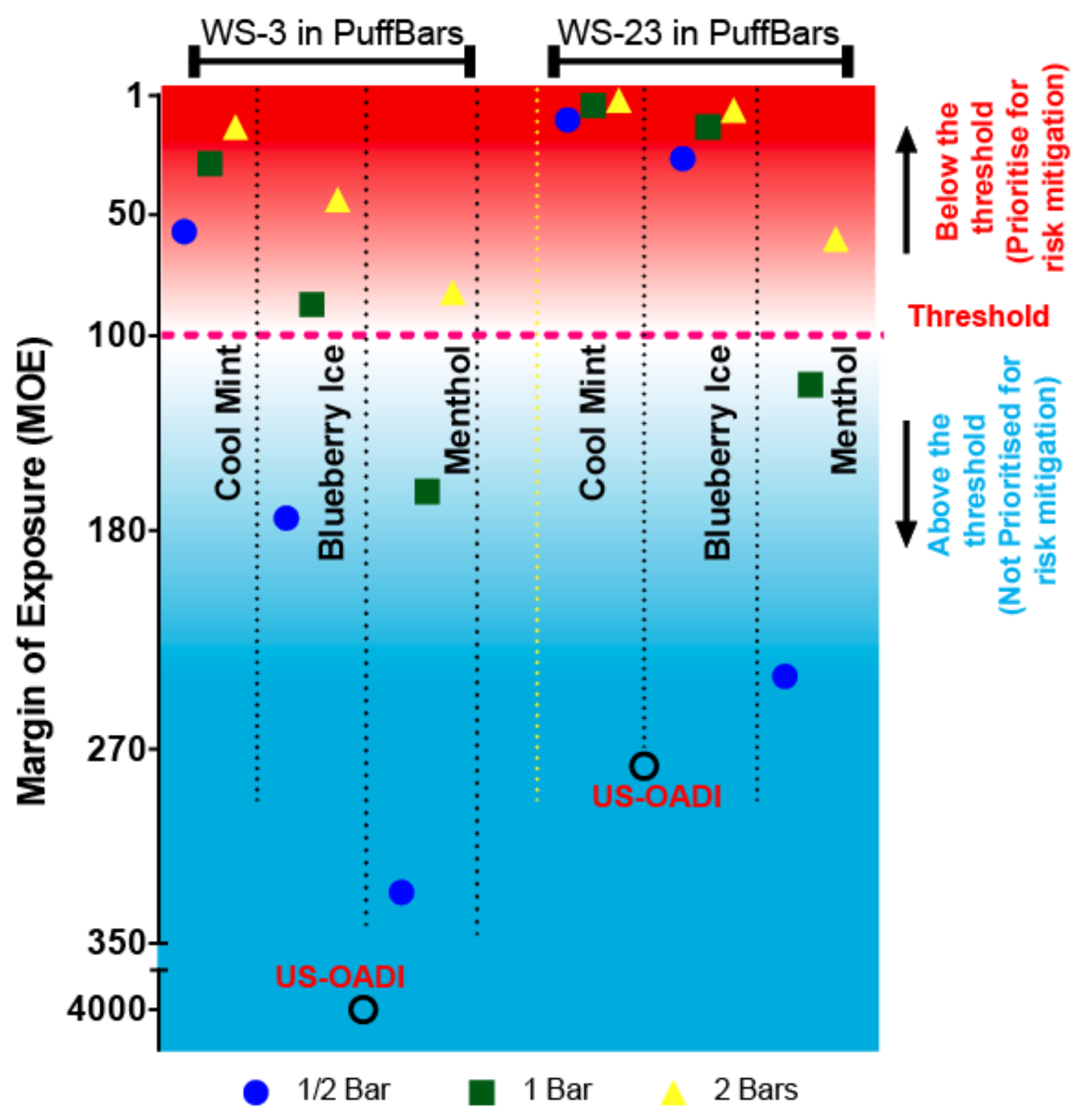

